\title{
Características Determinantes das Companhias do Novo Mercado que Adotam o Hedge Accounting
}

\section{Striking Features of the New Market Companies Adopting Hedge Accounting}

\author{
Leandro Augusto Toigo \\ Doutorando do Programa de Pós-Graduação em Ciências Contábeis e Administração \\ Centro de Ciências Sociais Aplicadas \\ Universidade Regional de Blumenau - Blumenau, SC \\ leandrotoigo@yahoo.com.br \\ Maria Margarete Brizolla \\ Doutoranda do Programa de Pós-Graduação em Ciências Contábeis e Administração \\ Centro de Ciências Sociais Aplicadas \\ Universidade Regional de Blumenau - Blumenau, SC \\ mbrizolla@al.furb.br \\ Francisco Carlos Fernandes \\ Professor Doutor do Programa de Pós-Graduação em Ciências Contábeis e Administração \\ Centro de Ciências Sociais Aplicadas \\ Universidade Regional de Blumenau - Blumenau, SC \\ fernandes.francisco@uol.com.br
}

\begin{abstract}
Resumo
Esta pesquisa teve por objetivo principal analisar as características de governança corporativa e financeiras que discriminam grupos de empresas que adotam hedge accounting no novo mercado para gestão de risco. Nesse sentido, realizou-se pesquisa descritiva junto ao sítio da BM\&FBOVESPA, conduzida por meio de análise documental dos demonstrativos financeiros de 31/12/2012, tais como as notas explicativas e relatórios da administração, também houve a coleta de dados no formulário de referência e na Economatica. A população corresponde as 128 companhias do nível de governança - novo mercado, sendo que a amostra constituída foi aleatória e probabilística, compreendendo 88 entidades. Utilizou-se um constructo sobre o CPC 40 que trata do hedge accounting, visando segmentar a amostra em empresas optantes ou não da contabilidade de hedge. Os resultados encontrados com a aplicação da correlação de Pearson e da regressão logística com os testes de Hosmer e Lemoshow (HLT) e do Teste Omnibus do Coeficiente do Modelo (OTMC), demonstraram que as empresas que apresentam concentração acionária, investidores estrangeiros e maior tamanho de ativos são as que adotam de forma mais significativa o CPC 40. Conclui-se, que as companhias brasileiras pertencentes ao novo mercado que adotam a prática de evidenciação contábil para demonstrar aprimoramento na gestão de risco dos investimentos dos acionistas, são empresas de grande porte com a estrutura de capital composta por investidor estrangeiro e representativa concentração acionária.
\end{abstract}

Palavras-chave: Gestão de risco. Hedge accounting. Governança corporativa. 


\begin{abstract}
This research had as main objective to analyze the corporate and financial governance characteristics that discriminate against groups of companies that adopt hedge accounting in the new market for risk management. In this sense, there was descriptive survey the site of BM\&FBOVESPA, conducted through desk review of the financial statements of 31/12/2012, including the explicative notes and management reports, there was also collecting data in reference form and Economatica. The population corresponds as 128 companies of the governance level - new market, and that the reserve sample was random and probabilistic, comprising 88 companies. We used a construct of the CPC 40 that deals with hedge accounting in order to segment the sample companies opting or not hedge accounting. The results of the application of Pearson's correlation and logistic regression with the Hosmer and Lemoshow tests (HLT) and Test Omnibus coefficient model (OTMC), have shown that companies with ownership concentration, foreign investors and larger assets are adopting more significantly CPC 40. It follows that Brazilian companies belonging to the new market that adopt the practice of accounting disclosure to demonstrate improvement in risk management of the investments of the shareholders, are large companies with the capital structure composed of foreign investor and representative shareholder wealth.
\end{abstract}

Keywords: Risk management. Hedge accounting. Corporate governance.

\title{
1 Introdução
}

O crescimento das corporações resultou na separação entre propriedade e gestão. Esse cenário é diferente daquele observado em um passado não muito distante, quando as empresas possuíam uma gestão centralizada, exercida principalmente pelos seus proprietários. Neste contexto, assegurar a harmonia entre os interesses dos gestores, proprietários e ainda garantir que esses interesses não esbarrem naqueles dos fornecedores, clientes e da sociedade em geral tornou-se cada vez mais difícil.

A OECD (2013) aborda que a estrutura de governança corporativa deve assegurar a evidenciação oportuna e precisa de todos os fatos relevantes referentes à companhia, inclusive da posição financeira, desempenho, participação acionária e governança. Com isso, percebese que a gestão de risco, evidenciação contábil e governança corporativa estão relacionadas, uma vez que o risco impacta no patrimônio das organizações e a evidenciação contábil é responsável por comunicar estes impactos aos usuários, que podem ser também os acionistas.

Inserido neste debate, a evidenciação desses elementos é relevante no sentido de auxiliar os usuários das informações contábeis na tomada de decisão. No contexto empresarial, entende-se a evidenciação como relevante para os gestores e investidores, uma vez que estes, frequentemente precisam decidir e aproveitar oportunidades de negócios (LAUDELINO, 2008). Destaca-se que o mercado de capitais esta ávido por informações que permitam um maior grau de segurança a respeitos da posição econômica e financeira das organizações, no intuito de assegurar melhor proteção aos investidores.

Uma forma de redução de riscos para as companhias é a adoção do CPC 40 e evidenciação das operações com hedge, as quais podem proporcionar maior segurança para o negócio e diferencial competitivo. Com esse intuito, destaca-se a importância de evidenciar contabilmente as operações com hedge (hedge accounting) e disponibilização das informações por meio dos relatórios contábeis aos stakeholders e mercado financeiro, 
objetivando transmitir a confiabilidade necessária que tende a proporcionar um diferencial competitivo (FERNANDES et al., 2012).

Dessa forma, a evidenciação, o hedge accounting e a governança corporativa estão sendo pesquisados (GUAY, 1999; HEALY; PALEPU, 2001; HO; WONG, 2001; GUAY; KOTHARI, 2003; GLAUM; KLÖCKER, 2011; ARAÚJO et al., 2011; FERNANDES et al., 2012; VAISSIÉ, 2012; OECD, 2013), entretanto são necessários mais estudos empíricos que visem contribuir para a relação entre esses temas. Fernandes et al. (2012), pesquisando o hedge accounting nos três níveis de GC nas companhias da Bolsa de Mercadorias e Futuros da Bolsa de Valores de São Paulo (BM\&FBOVESPA) em 2008-2011, identificaram que a divulgação é maior nas companhias do nível Novo Mercado.

Com base no exposto elaborou-se a seguinte pergunta de pesquisa: Quais características financeiras e de governança corporativa que discriminam o hedge accounting de empresas do novo mercado para a gestão de risco? Assim, o estudo objetiva investigar a evidenciação contábil do hedge (hedge accounting) e as características financeiras (próprias da empresa) e de governança corporativa. Com esse estudo, torna-se possível obter características específicas de companhias que estão no novo mercado, que zelam pelo aprimoramento de suas práticas de Governança e utilizam a evidenciação contábil para a gestão de risco, oferecendo mais segurança e transparência ao acionista com a adoção voluntária do hedge accounting.

A justificativa do estudo fundamenta-se na contribuição para o preenchimento da lacuna identificada na literatura científica da área de conhecimento, visando à identificação de características determinantes das companhias que praticam o hedge accounting no novo mercado. O estudo também é pertinente, uma vez que ao observar as pesquisas abordadas no na revisão de literatura, nenhuma atendeu aos objetivos que estão sendo propostos neste estudo.

\section{Revisão da literatura}

\subsection{Gestão de risco e governança corporativa}

A gestão de risco pode ser entendida como o processo pelo qual a gerência conduz o risco, aproveitando suas oportunidades na geração da lucratividade e competitividade nas organizações (BERNSTEIN, 1996). Porém, é necessário avaliar o risco frente às constantes mudanças sofridas no meio empresarial com o objetivo de minimizar impactos (BOGONI, FERNANDES, 2011).

Zonatto e Beuren (2010) identificaram as categorias de riscos evidenciadas no relatório da Administração de 2007 de empresas brasileiras que emitiram American Depositary Receipt - ADRs e utilizaram para isso amostra de 28 empresas com ADRs na Bolsa de Nova Iorque. A pesquisa utilizou sete categorias de riscos corporativos abordados pelo $\mathrm{COSO}$, sendo estes riscos estratégicos, riscos de mercado, riscos de crédito, riscos de liquidez, riscos operacionais, riscos legais e riscos de imagem. Como resultado a categoria de risco operacional foi a mais evidenciada com 20,72\% das observações.

O relatório Cadbury 1992 foi uma iniciativa política que legitimou a aplicação das práticas de controle da empresa para incluir a gestão de risco e questões de governança corporativa. A gestão de risco e a governança corporativa são influenciadas significativamente pelas políticas de controle empresarial e membro externo na composição do conselho de administração influencia a escolha dos diretores, portanto os mecanismos de governança tem interferência nas atividades estratégicas e definem os resultados dos controles contábil-financeiros, e ainda, a participação de um membro externo no conselho de administração promove alterações nas políticas organizacionais (BHIMARI, 2009). 
A crise financeira de 2007/2008 proporcionou severas críticas à função da governança corporativa na gestão de risco das organizações. O estudo de Aebi, Sabato, Schmid, (2010) investigou a relação da gestão de risco com a governança corporativa, avaliou se o Gestor de risco (CRO) se reportando ao Diretor executivo ou ao conselho de administração mudaria o desempenho do banco durante a crise. Os resultados indicam que os bancos nos quais o Gestor de Risco se reportou diretamente ao conselho de administração tiveram melhores resultados (ROE e ROI) durante a crise.

Lang e Jagtiani (2010) abordam que a Crise financeira imobiliária americana em 2007 foi provocada pela deficiência na gestão de risco e governança corporativa, momento em que muitas companhias estavam concentrando seus investimentos em um único tipo de título e isso foi uma demonstração de falha na governança. O nível de governança existente não conseguiu evitar a falta de transparência com estas operações no ariscado mercado imobiliário americano, e os executivos recebiam gratificação com o retorno dessas operações, o que ocorria devido à falta de transparência das instituições. Ainda, um dos grandes motivos que levou as instituições financeiras a arriscarem tanto, foi o excesso de confiança em que as empresas eram grandes demais para falir, e com isso houve a negligência do risco. Os mesmos concluem com a recomendação que os incentivos salariais dos executivos devem levar em conta o risco e a transparência de suas decisões, e que os executivos também devem ser responsabilizados por seus atos.

Silveira (2013) relata que a crise financeira sofrida pela Sadia S.A. poderia ter sido evitada se a Governança Corporativa tivesse realmente sido colocada em prática na avaliação do risco, o autor destaca série de falhas de governança e gestão de risco, sendo que uma delas foi a falta de transparência. Segundo o mesmo, os resultados com derivativos poderiam ter sido apresentados de forma bem mais transparentes aos investidores, a legislação brasileira era frouxa em relação à evidenciação contábil dos derivativos, fato que fez a empresa optar por registrar os ganhos financeiros com derivativos em receitas operacionais e não como receitas financeiras, escondendo assim, os resultados com este tipo de operação e consequientemente, a grande exposição da companhia ao risco com esse tipo de operação.

A crise financeira foi um grande indicador das falhas e fraquezas nos arranjos de governança corporativa, sendo que a referida governança não serviu para realizar a adequada gestão do risco nas empresas financeiras. A maior regulamentação da legislação contábil mostrou-se insuficiente para mitigar os riscos em algumas organizações. Por último, mas não menos importante, o sistema de remuneração dos diretores executivos não estava alinhado ao risco das empresas e estratégias de longo prazo. O estudo de Kirkpatrick (2009) sugere maior atuação dos conselhos da governança e a necessária atenção à gestão de risco, não somente em empresas financeiras.

\subsection{Características financeiras e de governança corporativa}

Quanto às boas características ou práticas de GC, o IBGC (2010) enfatiza que elas aumentam a independência do conselho de administração, considerando, principalmente, o aumento no número de conselheiros não executivos e a separação das funções de CEO e presidente do conselho de administração (Dualidade). Segundo a mesma fonte, o Conselho de Administração é órgão colegiado encarregado do processo de decisão de uma organização em relação ao seu direcionamento estratégico e o principal componente do sistema de governança. Ainda, o mesmo é o elo entre a propriedade e a gestão, recebe poderes dos sócios e presta contas a eles.

Labelle (2002) contribui para o debate, fornecendo evidências empíricas para os reguladores sobre os incentivos para algumas empresas a se envolver em uma melhor qualidade de práticas de governança corporativa, com pesquisas no Canadian Institute of 
Chartered Accountants (CICA) e publicações de 1996 e 1997. Assim, exceto para o tamanho e estrutura de propriedade, não foram encontradas relações consistentes e significativas entre a qualidade e declarações de práticas de governança corporativa, tais como: a proporção de diretor independente, dualidade e nível de atividades de financiamento.

Jiang, Habib e Hu (2010) em seu estudo, abordam o impacto de diferentes níveis de concentração acionária na assimetria da informação proposta pela evidenciação voluntária em companhias da Nova Zelândia. O estudo tenta ampliar esta linha de pesquisa, analisando três concentrações de propriedade, relacionando a concentração de capital e a evidenciação voluntária, de modo a revelar que a maior concentração de propriedade está associada diretamente com a maior assimetria de informação. Segundo o mesmo autor, quando a divulgação voluntária é levada em conta, os resultados demonstram que as divulgações reduzem significativamente a assimetria da informação e os riscos associados à concentração de propriedade. Assim, os resultados destacam a importância da evidenciação em estrutura de capital concentrada, e sua importância na redução da assimetria da informação e aumento da eficiência do mercado de ações da Nova Zelândia.

Conforme Tan e Keeper (2008), os investidores institucionais por meio de ações de propriedade concentrada, juntamente com a força financeira e competências da instituição são capazes de efetivamente superar o problema da participação difusa. São exemplos de investidores institucionais: as instituições financeiras, as companhias de seguros, os fundos de pensões, os bancos, as sociedades de investimentos e outras qualificadas em lei.

Haniffa e Cooke (2002) constataram que nas companhias da Malásia ocorreram relações positivas entre a proporção de ações possuídas por investidores estrangeiros e o nível de disclosure, sendo que, para os autores, diante da existência de investidores estrangeiros, existe uma maior necessidade de disclosure, como uma forma de monitoramento das ações dos referidos gestores.

$\mathrm{Na}$ maioria dos países a propriedade concentrada é a estrutura predominante nas companhias de capital aberto, sendo que isso muda o foco dos estudos de agência para a relação entre os acionistas controladores e os minoritários. Dessa forma, a abordagem da Teoria da Agência pela expressão principal-agente não se restringe apenas a relação do proprietário e administrador, tem caráter amplo e alcança a relação entre acionistas minoritários e majoritários (LA PORTA et al., 1999).

Embora a participação dos investidores institucionais e estrangeiros nas empresas brasileiras seja cada vez mais significativa, Silveira (2002, p. 31) acrescenta que "a forte concentração das ações com direito a voto é característica fundamental do modelo de governança das companhias abertas brasileiras, com uma ausência quase total de empresas de propriedade pulverizada".

Segundo IBGC (2010, p. 43) a característica de governança corporativa de a empresa possuir o Comitê de Auditoria surge para "analisar as demonstrações financeiras, promover a supervisão e a responsabilização da área Financeira e garantir que a Diretoria desenvolva controles internos confiáveis". Nesse sentido, Ho e Wong (2001) investigam mecanismos de governança e o nível de evidenciação voluntário, sendo que, os mecanismos foram: a existência do comitê de auditoria, proporção de membros independentes do conselho de administração e participação da família controladora no conselho de administração. Os autores identificaram que há relação positiva entre a existência do comitê de auditoria e o nível de evidenciação e relação negativa entre o nível de evidenciação e o percentual de membros internos e da família no Conselho de Administração, e ainda, o maior número de conselheiros externos e independentes é visto como uma forma de monitorar melhor os diretores da companhia, resultando em maior evidenciação voluntária de informações empresariais devido à função de controle desempenhada pelo conselho. 
A auditoria externa, também é considerada capaz de influenciar nas práticas de disclosure corporativo. As grandes empresas de auditoria investem mais que as menores em manter sua imagem, pois tendem a perder mais em casos de danos à sua reputação e têm maior número de clientes, portanto são menos dependentes de cada um deles em individual, o que as leva a serem mais comprometidas com a qualidade de seu trabalho que aquelas empresas menores (De ANGELO, 1981). Essa situação tem gerado diversos estudos, como o de Ahmed e Nicholls (1994), sendo que este comprovou a existência de tal relação.

Sobre características financeiras e próprias das empresas, Wallace, Naser e Mora (1994) e Wallace e Naser (1995) abordam em seus estudos sobre o disclosure que o tamanho da empresa é um forte determinante para o a evidenciação, pois empresas grandes evidenciam mais informações do que empresas menores. Isso ocorre devido ao maior número de stakeholders envolvidos com a empresa. Procianoy e Schnorrenberger (2004), em estudo realizado junto às companhias brasileiras listadas na BM\&FBOVESPA, nos anos de 1995 a 2000 verificaram que existe uma influência entre a estrutura de controle acionário sobre as decisões de estrutura de capital. E ainda, o estudo conclui que as empresas que apresentam maior concentração em sua estrutura de controle tendem a apresentar aversão ao endividamento e risco financeiro.

Silva (2004) pesquisou os efeitos da estrutura de controle e propriedade no valor de mercado na estrutura de capital e na política de distribuição de dividendos das empresas brasileiras e os resultados revelaram que existe relação positiva, e estatisticamente significativa, entre a estrutura de governança, valor de mercado, alavancagem financeira e as políticas de dividendos das empresas. Wallace e Naser (1995) afirmam por meio de seu estudo que a alta liquidez das empresas está associada com o maior grau de disclosure, por outro lado, Wallace Naser e Mora (1994) argumentam que as companhias com baixa liquidez tendem a divulgar um número maior de informações para justificar sua situação financeira, os próprios autores abordam que os resultados não são conclusivos.

\subsection{Evidenciação contábil e hedge accounting}

$\mathrm{Na}$ abordagem sobre as características financeiras e de governança para a gestão de risco, o disclosure (evidenciação contábil) e a estrutura patrimonial tornaram-se temas amplamente citados nos estudos de diversos pesquisadores, conforme se apresentou na seção anterior. Nesta seção aborda-se mais detalhadamente o tema disclosure (evidenciação contábil) e relaciona-se este com o hedge accounting.

Healy e Palepu (2001) acreditam que a demanda por relatórios financeiros surge pela assimetria da informação no conflito de agência entre gestores e investidores externos, e ainda, que há mudanças significativas no ambiente econômico, inovação tecnológica, surgimento de organizações em rede, mudanças na economia de negócios de empresas de auditoria e analistas financeiros e globalização do mercado de capitais. Estas mudanças tem o potencial de alterar a natureza dos relatórios e divulgação, criando oportunidades ricas para a pesquisa.

Iatridis (2008) estuda as características financeiras de empresas do Reino Unido que fornecem divulgações extensas, identificando o impacto financeiro, analisa os atributos financeiros de empresas que divulgam informações sobre questões contábeis importantes, incluindo a exposição ao risco, as mudanças nas políticas contábeis e a utilização de normas e práticas de cobertura dos relatórios financeiros internacionais. Os resultados indicam que a divulgação de informações contábeis não prejudica a rentabilidade das empresas, ao contrário, as empresas que fornecem divulgações contábeis detalhados tendem a apresentar maior rentabilidade e o uso das normas internacionais para os relatórios financeiros aumenta a qualidade e a comparabilidade das demonstrações, em virtude de promover a consistência e 
confiabilidade dos relatórios financeiros facilitando as empresas na obtenção de capital internacional.

Para Sloan (2001) a contabilidade pode ser considerada um elemento importante no processo de governança, pois as instituições evoluíram no sentido de fornecer mais informações financeiras, sendo que estas informações compreendem inputs importantes para o processo de governança. Deste modo, a evidenciação contábil pode ser definida como a divulgação por parte da empresa de todas as informações positivas e negativas que tenham relevância para os usuários de tais informações, e que proporcionem transparência e segurança aos investimentos realizados pelo acionista nas companhias.

Com base nisso é oportuno observar: o hedge não é um meio de geração de lucros, mas sim, um método de se evitar riscos desnecessários, aumentando o bem-estar dos indivíduos e empresas envolvidas. Araujo et al. (2011) analisaram o nível de adesão do hedge accounting em companhias listadas na BM\&FBOVESPA, que faziam parte do IBrx-100. Os autores verificaram que $71,60 \%$ das empresas declararam que possuíam operações de hedge. Dessas, apenas $29,31 \%$ divulgaram ter designado ao menos uma de suas operações com derivativos como hedge accounting, 94\% evidenciaram informações de hedge da operação. Do restante das empresas pesquisadas, apenas duas de 58 companhias apresentaram informações sobre a metodologia de cálculo efetivo do hedge.

Fernandes et al. (2012) realizaram um estudo que buscou avaliar a conformidade com os critérios normativos de evidenciação estabelecidos no CPC 40 sobre a contabilidade de hedge em companhias abertas listadas no Índice de Sustentabilidade Empresarial (ISE) da BM\&FBovespa. Os resultados do estudo demonstram que a contabilidade de hedge não recebeu a devida atenção do meio empresarial, porém o número de empresas que vem adotando a metodologia vem crescendo nos últimos anos, especificamente em 2008-2011. Dentre as empresas da pesquisa, aquelas listadas no novo mercado foram as que mais possuíam contabilidade de hedge e que divulgavam o maior número de informações.

Glaum e Klöcker (2011) analisaram a evidenciação da contabilidade de hedge e sua influência no comportamento em sociedades não financeiras alemãs e suíças. Em termos amostrais, concluíram que $72 \%$ delas utilizam a contabilidade de hedge. A evidenciação está associada às exigências estabelecidas nas normas internacionais. Observaram que mais da metade das empresas que utilizam a contabilidade de hedge e informaram que as suas regras contábeis influenciaram na evidenciação. Nesta mesma pesquisa, as empresas que possuem maior probabilidade de serem afetadas são aquelas que fazem operações de hedge eventualmente.

De maneira geral, pode-se considerar que houve avanços nos últimos anos nos processos de reconhecimento, mensuração e divulgação do hedge accounting, a preocupação pelo tema vem crescendo e consecutivamente sua evidenciação contábil. O meio acadêmico também contribui com suas constantes discussões. Uma vez finalizada a discussão teórica, o estudo segue na exposição dos procedimentos metodológicos que nortearam o presente artigo.

\section{Metodologia de pesquisa}

Para atender ao objetivo proposto de identificar características financeiras e de governança corporativa que discriminam o hedge accounting de empresas do novo mercado para a gestão de risco utilizou-se como base o estabelecido pelo CPC 40 (R1) para a definição do hedge accouting. Quanto aos procedimentos de pesquisa, o formato é documental e no que concerne ao método de abordagem do problema proposto, o estudo é quantitativo, pois visa analisar a relação entre as variáveis de características financeiras e de governança corporativa e o hedge accounting. A pesquisa caracteriza-se também como descritiva.

A população da pesquisa foi constituída pelas 128 companhias listadas na BM\&FBOVESPA em 14/06/2013 que estão no nível de governança corporativa - Novo Toigo, L. A.; Brizolla, M. M.; Fernandes, F. C. 
Mercado. Para a constituição da amostra, foram excluídas as instituições financeiras, por serem regidas por regras próprias do Conselho Monetário Nacional. As holdings, por serem empresas que representam outras em um grupo de empresas, o que duplicaria a avaliação e contagem de hedge accounting na pesquisa, também foram excluídas da amostra. Com população ajustada de 112 empresas foi aplicado o teste de amostra e com nível de confiança de $95,5 \%$ e erro amostral de $5 \%$ foi obtida a amostra de 88 empresas, selecionadas aleatoriamente.

Com a definição da amostra e para atender ao tema central da pesquisa, iniciou-se a avaliação da evidenciação da contabilidade de hedge com a aplicação do constructo elaborado por CPC 40 (R1). Os relatórios analisados foram o Relatório da Administração e as Notas Explicativas do exercício social de 2012, disponibilizados pelo sítio da BM\&FBOVESPA. Por análise de conteúdo dos referidos relatórios foram coletados os resultados da aplicação do constructo das 88 empresas da amostra, o que identificou a segmentação de dois grupos: (a) composto por 62 companhias de dois tipos: não apresentavam operações de hedge e apresentavam operações de hedge, porém não adotavam as normas contábeis para o hedge accounting e (b) composto por 26 companhias que operavam com hedge de diferentes naturezas e adotavam as normas contábeis para o hedge accounting.

Em conjunto com o nível de evidenciação da contabilidade de hedge do novo mercado, ou seja, os dois grupos de empresas, coletaram-se informações de características de Governança Corporativa (Quadro 1) que pudessem discriminar a amostra de empresas do novo mercado que evidenciam adequadamente a contabilidade de hedge.

\begin{tabular}{|c|c|c|}
\hline \multicolumn{3}{|c|}{ uadro 1 - Características de Governança Corporativa } \\
\hline Variável & Descrição da variável & Autor (ANO) \\
\hline $\begin{array}{l}\text { EXT - Composição do } \\
\text { Conselho de } \\
\text { Administração. }\end{array}$ & Total de membros do Conselho de Administração & $\begin{array}{c}\text { Ho, Wong (2001); Dutra, Saito } \\
\text { (2002); IBGC (2010); Fraga, Silva } \\
\text { (2012). }\end{array}$ \\
\hline $\begin{array}{l}\text { DUAL - Estrutura de } \\
\text { liderança do Conselho } \\
\text { de Administração. }\end{array}$ & $\begin{array}{l}\text { "1" se há acumulação das funções de presidente do } \\
\text { conselho de administração e CEO da empresa, e "0" } \\
\text { se não. }\end{array}$ & IBGC (2010). \\
\hline $\begin{array}{l}\text { CAUD - Comitê de } \\
\text { Auditoria }\end{array}$ & "1" se há um comitê de auditoria e "0" se não & IBGC (2010); Ho, Wong (2001). \\
\hline $\begin{array}{l}\text { BIG4 - Auditoria } \\
\text { Externa }\end{array}$ & $\begin{array}{l}\text { "1" se as demonstrações contábeis da empresa foram } \\
\text { auditadas por uma das } 4 \text { maiores empresas de } \\
\text { auditoria (PricewaterhouseCoopers, Deloitte Touche } \\
\text { Tohmatsu, Ernest \& Young e KPMG) e "0" se não. }\end{array}$ & De Angelo (1981) \\
\hline $\begin{array}{l}\text { INST - Investidores } \\
\text { Institucionais }\end{array}$ & $\begin{array}{l}\text { \% Participação acionária de investidores } \\
\text { institucionais na empresa. }\end{array}$ & $\begin{array}{l}\text { Tan, Keeper (2008); Moura, } \\
\text { Macêdo e Hein (2011). }\end{array}$ \\
\hline $\begin{array}{l}\text { ESTR - Investidores } \\
\text { Estrangeiros }\end{array}$ & $\begin{array}{c}\text { \% Participação acionária de investidores } \\
\text { estrangeiros na empresa. }\end{array}$ & $\begin{array}{l}\text { Haniffa, R.M.; Cooke, T. E } \\
\text { (2002). }\end{array}$ \\
\hline $\begin{array}{l}\text { CONC - Concentração } \\
\text { Acionária }\end{array}$ & $\begin{array}{c}\text { \% Participação acionária dos } \\
4 \text { Maiores Acionistas }\end{array}$ & $\begin{array}{l}\text { Labelle (2002); IBGC (2010), } \\
\text { Jiang, Habib e Hu (2010). }\end{array}$ \\
\hline
\end{tabular}

Fonte: Dados da pesquisa

Pela abordagem do Quadro 1, observa-se que quase todos dos dados das características de governança estão disponíveis no formulário de referência do sítio da BMF\&BOVESPA, excluindo-se a concentração acionária que foi extraída da Economatica. Juntamente com as informações de hedge accounting, características de governança, foram coletadas informações sobre características particulares e financeiras das companhias, sendo estas extraídas da Economatica conforme se apresenta no Quadro 2.

Quadro 2 - Características financeiras das companhias 


\begin{tabular}{|l|c|c|}
\hline TAM - Tamanho da empresa & Total do ativo & $\begin{array}{c}\text { Wallace, Naser (1995); Wallace, } \\
\text { Naser, Mora (1994) }\end{array}$ \\
\hline END - Grau de endividamento & $\frac{\text { Total das dívidas da empresa }}{\text { Total do Ativo }}$ & $\begin{array}{c}\text { Procianoy e Schnorrenberger } \\
\text { (2004) }\end{array}$ \\
\hline ROA - Lucratividade & $\frac{\text { Lucro líquido disponível para os acionistas }}{\text { Total do ativo. }}$ & Silva (2004) \\
\hline LIQ - Liquidez & $\frac{\text { Ativo Circulante + Realizável a Longo Prazo }}{\text { Passivo Circulante + Exigível a Longo Prazo }}$ & $\begin{array}{c}\text { Wallace, Naser (1995); Wallace, } \\
\text { Naser, Mora (1994) }\end{array}$ \\
\hline
\end{tabular}

Fonte: Dados da pesquisa

Assim, relacionou-se o hedge accounting de empresas que estão inseridas no nível de governança corporativa novo mercado com suas próprias características financeiras e de governança corporativa. $\mathrm{Na}$ análise dos dados foi aplicada a estatística descritiva e a regressão logística com o auxílio do programa SPSS Statistics. Finalizada a descrição da parte metodológica que norteou o presente estudo, parte-se para a análise dos dados da pesquisa realizada.

\section{Análise dos dados}

\subsection{Estatística descritiva}

Com base nos relatórios de referência de 31/12/2012 das empresas estudadas foram extraídas informações financeiras e de governança corporativa para a caracterização das mesmas. Também foi realizada a análise de conteúdo do relatório da administração e notas explicativas sobre a adoção do hedge accounting. A partir desses dados foi realizada a análise descritiva conforme a Tabela 1, que considerou cada característica coletada como uma variável distinta.

\begin{tabular}{l|r|r|r|r}
\multicolumn{2}{c}{ Tabela 1 - Estatísticas descritivas das variáveis } \\
\hline & \multicolumn{1}{|c|}{ Mínimo } & \multicolumn{1}{c}{ Máximo } & $\begin{array}{c}\text { Média } \\
\text { estatística }\end{array}$ & $\begin{array}{c}\text { Desvio } \\
\text { padrão }\end{array}$ \\
\hline CONC & 6,00 & 97,40 & 56,50 & 17,91 \\
\hline HEDGE & 2,00 & 3,00 & - & - \\
\hline EXT & 66,66 & 100,00 & 92,57 & 9,38 \\
\hline DUAL & 0,00 & 1,00 & - & - \\
\hline CAUD & 0,00 & 1,00 & - & - \\
\hline BIG4 & 0,00 & 1,00 & - & 20,97 \\
\hline INST & 0,00 & 81,25 & 24,56 & 13,05 \\
\hline ESTR & 0,00 & 62,00 & 7,96 & 16,98 \\
\hline TAM & $120.679,00$ & $35.926 .521,00$ & $4.153 .461,56$ & $6.146 .125,25$ \\
\hline END & 0,00 & 60,80 & 21,69 & 10,68 \\
\hline ROA & $-53,96$ & 27,06 & 3,84 & 2,93 \\
\hline LIQ & 0,00 & 20,20 & 1,78 &
\end{tabular}

Pelas informações dispostas na Tabela 1 constata-se que a concentração acionária (CONC) das empresas pesquisadas foi de 56,5\%, em média. Para a coleta de informações sobre o hedge accounting (HEDGE) nas notas explicativas e relatório da administração foram utilizadas as indicações 2 e 3 , sendo que 2 indicou os não adotantes e 3 os adotantes do hedge accounting. Para a variável de composição por membros externos no conselho de administração (EXT) foi constatada a variação percentual de $66,66 \%$ a $100 \%$ para as empresas estudadas, sendo apresentado percentual médio elevado de 92,57\%. Para as variáveis estrutura de liderança do conselho de administração (DUAL), comitê de auditoria (CAUD), empresas de auditoria (BIG4) e hedge accounting (HEDGE) foi utilizado dummy 0 e 1, assim não foi calculado a sua média e nem seu desvio padrão. A variável (INST) 
representa a informação do percentual de participação de investidor institucional na composição do capital da companhia e verificou-se a média de $24,56 \%$, podendo ser considerado percentual relevante. A participação do investidor estrangeiro na composição do capital social (ESTR) foi de 7,56\%, em média, alcançando a participação máxima de $62 \%$. Para a variável tamanho das empresas (TAM) constatou-se o valor médio de $\mathrm{R} \$ 4.153 .461,56$, tendo a menor empresa o ativo total de $\mathrm{R} \$ 120.679,00$, e a maior $\mathrm{R} \$ 35.926 .521,00$ (valores TAM x 1.000). O endividamento das companhias (END) foi de $21,64 \%$, em média. O retorno sobre os ativos (ROA) foi em média de $3,84 \%$. E por último, a liquidez corrente (LIQ) foi de 1,78 , em média.

Realizando a análise de correlação entre as características ou variáveis por meio da Tabela 2, verificou-se que grande parte das variáveis de governança corporativa e financeira está positivamente relacionada com as empresas que adotam hedge accounting, a exceção ocorre com a variável Retorno dos Ativos (ROA).

Pela Tabela 2, observaram-se as correlações encontradas das variáveis com o HEDGE. Constatou-se assim, a correlação positiva e significativa no nível de 0,01 entre o hedge accounting (HEDGE) e o Tamanho da companhia (TAM) como a mais relevante com o percentual de $37,8 \%$. Na sequencia, foi constatada a relevância entre a correlação de hedge accounting (HEDGE) com investidor estrangeiro, com percentual de 26,4\%, com significância ao nível de 0,05 . Por último, também foi verificada a existência de correlação relevante, positiva e significante ao nível 0,05 entre as variáveis de hedge accounting (HEDGE) e concentração acionária (CONC), com percentual de 25,2\% de correlação. As demais variáveis observadas que apresentaram correlação positiva ou negativa com o hedge accounting (HEDGE) não apresentam significância, conforme Tabela 2.

Tabela 2 - Matriz de correlação das variáveis

\begin{tabular}{|c|c|c|c|c|c|c|c|c|c|c|}
\hline & & CONC & HEDGE & EXT & INST & ESTR & TAM & END & ROA & LIQ \\
\hline \multirow{2}{*}{ CONC } & Correlação & 1 & $252^{*}$ & ,029 &,- 004 &,- 105 &,- 044 &,- 036 &,- 198 &, 127 \\
\hline & Sig. & & ,018 & ,786 & ,968 & ,329 &, 682 & ,739 & ,065 & 239 \\
\hline \multirow{2}{*}{ HEDGE } & Correlação & & 1 & 122 & 125 & ,264* &, $\mathbf{3 7 8}^{* *}$ &, 178 &,- 092 & 022 \\
\hline & Sig. & & & 258 & 247 & 013 &, 000 & ,097 & ,393 & 838 \\
\hline \multirow{2}{*}{ EXT } & Correlação & & & 1 & ,057 & ,097 &, 102 &,- 062 &,- 129 & ,147 \\
\hline & Sig. & & & & ,595 & 370 & ,342 & ,568 & ,229 &, 172 \\
\hline \multirow{2}{*}{ INST } & Correlação & & & & 1 & $463^{* *}$ &, 030 & ,051 &,$- 220^{*}$ & ,097 \\
\hline & Sig. & & & & &, 000 & ,781 & ,634 & ,039 &, 370 \\
\hline \multirow[b]{2}{*}{ ESTR } & Correlação & & & & & 1 &, 021 &,- 165 &,- 022 &, $407^{* *}$ \\
\hline & Sig. & & & & & & 844 &, 124 & 841 &, 000 \\
\hline \multirow[t]{2}{*}{ TAM } & Correlação & & & & & & 1 &, 102 & 076 &,- 109 \\
\hline & Sig. & & & & & & & ,343 & ,479 & 311 \\
\hline \multirow{2}{*}{ END } & Correlação & & & & & & & 1 &,$- 338^{* *}$ &,$- 412^{* * *}$ \\
\hline & Sig. & & & & & & & & 001 &, 000 \\
\hline \multirow[b]{2}{*}{ ROA } & Correlação & & & & & & & & 1 & ,036 \\
\hline & Sig. & & & & & & & & & 740 \\
\hline \multirow{2}{*}{ LIQ } & Correlação & & & & & & & & & 1 \\
\hline & Sig. & & & & & & & & & \\
\hline \multicolumn{11}{|c|}{ *. A correlação de Pearson é significativa no nível 0,05 (2 extremidades). } \\
\hline \multicolumn{11}{|c|}{ **. A correlação de Pearson é significativa no nível 0,01 (2 extremidades). } \\
\hline
\end{tabular}

Com os resultados observados percebe-se que há um indicativo que as companhias pertencentes ao nível de governança do novo mercado da BM\&FBOVESPA, que operam com hedge e adotam o hedge accounting são caracterizadas por apresentarem elevado valor dos seus ativos, estrutura de capital constituída por investidor estrangeiro e elevada concentração 
acionária. A Tabela 2 não apresentou as variáveis estrutura de liderança do conselho de administração (DUAL), comitê de auditoria (CAUD), empresas de auditoria (BIG4) e hedge accounting (HEDGE) que utilizam dummy 0 e 1, por não ser adequado estatisticamente analisá-las pela Correlação de Pearson. Para atender ao objetivo da pesquisa, torna-se conveniente aplicar a regressão logística e analisar os resultados do Quadro 2.

\subsection{Regressão Logística}

A regressão logística foi realizada aplicando-se a todas as variáveis, visando atender ao objetivo de pesquisa. Para a determinação do modelo de regressão logística adotou-se o modelo bachward stepwise de Wald, que seleciona as variáveis significantes, excluindo as não significantes. Este modelo permite identificar as variáveis que mais contribuem para o modelo (FÁVERO et al., 2009).

Com base no problema de pesquisa deste estudo, formou-se o pressuposto que apenas algumas variáveis financeiras e de governança corporativa poderiam apresentar correspondência significativa ou predizer grupos de uma variável predita de hedge accounting, para isso, adotou-se a regressão logística para análise dos dados. Para a formação do modelo de regressão logística formaram-se 9 etapas, em cada uma delas foi extraída uma variável, sendo que na etapa 9 foram encontradas as variáveis adequadas (Tabela 3).

$\mathrm{Na}$ Tabela 3 são apresentados cada etapa da regressão, juntamente com o valor do coeficiente $\beta$, o grau de significância, o percentual de aproximação do modelo e os resultados dos Testes de Hosmer e Lemoshow (HLT) e do Teste Omnibus do Coeficiente do Modelo (OTMC).

Tabela 3 - Resultados do modelo de regressão logística

\begin{tabular}{|c|c|c|c|c|c|c|c|c|}
\hline \multirow[t]{2}{*}{ Etapas } & \multirow[t]{2}{*}{ Variáveis } & \multirow[t]{2}{*}{ B } & \multirow{2}{*}{ Significância } & \multirow{2}{*}{$\begin{array}{c}\% \\
\text { Corretamente } \\
\text { classificado }\end{array}$} & \multicolumn{2}{|c|}{$\begin{array}{l}\text { Teste de Hosmer e } \\
\text { Lemeshow }\end{array}$} & \multicolumn{2}{|c|}{ Teste de Omnibus } \\
\hline & & & & & $\begin{array}{l}\text { Qui- } \\
\text { quadrado }\end{array}$ & $\begin{array}{l}\text { Signifi- } \\
\text { cância }\end{array}$ & $\begin{array}{c}\text { Qui- } \\
\text { quadrado }\end{array}$ & $\begin{array}{l}\text { Signifi- } \\
\text { cância }\end{array}$ \\
\hline \multirow{12}{*}{1} & CONC & 0,056 & 0,010 & \multirow{12}{*}{78,4} & \multirow{12}{*}{3,642} & \multirow{12}{*}{0,888} & \multirow{12}{*}{28,895} & \multirow{12}{*}{0,002} \\
\hline & EXT & 0,092 & 0,004 & & & & & \\
\hline & DUAL & $-0,116$ & 0,152 & & & & & \\
\hline & CAUD & $-2,950$ & 0,073 & & & & & \\
\hline & BIG4 & 0,112 & 0,863 & & & & & \\
\hline & INST & $-0,018$ & 0,988 & & & & & \\
\hline & ESTR & $-0,013$ & 0,391 & & & & & \\
\hline & TAM & 1,982 & 0,004 & & & & & \\
\hline & END & 0,019 & 0,349 & & & & & \\
\hline & ROA & 0,005 & 0,862 & & & & & \\
\hline & LIQ & $-0,107$ & 0,340 & & & & & \\
\hline & Constante & $-5,701$ & 0,485 & & & & & \\
\hline \multirow{11}{*}{2} & CONC &, 056 & 0,009 & \multirow{11}{*}{78,4} & \multirow{11}{*}{3,640} & \multirow{11}{*}{0,888} & \multirow{11}{*}{28,895} & \multirow{11}{*}{0,001} \\
\hline & ESTR & ,092 & 0,004 & & & & & \\
\hline & EXT &,- 116 & 0,151 & & & & & \\
\hline & DUAL & $-2,949$ & 0,073 & & & & & \\
\hline & CAUD &, 112 & 0,862 & & & & & \\
\hline & INST &,- 014 & 0,387 & & & & & \\
\hline & TAM & 1,981 & 0,004 & & & & & \\
\hline & END & ,019 & 0,348 & & & & & \\
\hline & ROA & 005 & 0,862 & & & & & \\
\hline & LIQ &,- 107 & 0,339 & & & & & \\
\hline & Constante & $-5,702$ & 0,485 & & & & & \\
\hline \multirow{2}{*}{3} & CONC &, 056 & 0,009 & \multirow{2}{*}{78,4} & \multirow{2}{*}{4,400} & \multirow{2}{*}{0,819} & \multirow{2}{*}{28,865} & \multirow{2}{*}{0,001} \\
\hline & ESTR & ,092 & 0,004 & & & & & \\
\hline
\end{tabular}

Toigo, L. A.; Brizolla, M. M.; Fernandes, F. C. 


\begin{tabular}{|c|c|c|c|c|c|c|c|c|}
\hline & EXT &,- 113 & 0,151 & & & & & \\
\hline & DUAL & $-2,882$ & 0,071 & & & & & \\
\hline & INST &,- 013 & 0,389 & & & & & \\
\hline & TAM & 1,992 & 0,004 & & & & & \\
\hline & END & ,018 & 0,356 & & & & & \\
\hline & ROA &, 005 & 0,869 & & & & & \\
\hline & LIQ &,- 105 & 0,345 & & & & & \\
\hline & Constante & $-6,036$ & 0,447 & & & & & \\
\hline \multirow{9}{*}{4} & CONC &, 055 & 0,008 & \multirow{9}{*}{78,4} & \multirow{9}{*}{5,741} & \multirow{9}{*}{0,676} & \multirow{9}{*}{28,838} & \multirow{9}{*}{0,000} \\
\hline & ESTR & ,092 & 0,004 & & & & & \\
\hline & EXT &,- 113 & 0,149 & & & & & \\
\hline & DUAL & $-2,876$ & 0,071 & & & & & \\
\hline & INST &,- 014 & 0,359 & & & & & \\
\hline & TAM & 2,004 & 0,003 & & & & & \\
\hline & END & ,017 & 0,354 & & & & & \\
\hline & LIQ &,- 105 & 0,344 & & & & & \\
\hline & Constante & $\begin{array}{l}-5,973 \\
\end{array}$ & 0,449 & & & & & \\
\hline \multirow{8}{*}{5} & CONC & ,053 & 0,009 & \multirow{8}{*}{80,7} & \multirow{8}{*}{10,009} & \multirow{8}{*}{0,264} & \multirow{8}{*}{27,948} & \multirow{8}{*}{0,000} \\
\hline & ESTR & 079 & 0,005 & & & & & \\
\hline & EXT &,- 104 & 0,180 & & & & & \\
\hline & DUAL & $-2,648$ & 0,090 & & & & & \\
\hline & TAM & 1,969 & 0,004 & & & & & \\
\hline & END &, 014 & 0,432 & & & & & \\
\hline & LIQ &,- 095 & 0,392 & & & & & \\
\hline & Constante & $-6,731$ & 0,393 & & & & & \\
\hline \multirow{7}{*}{6} & CONC & 051 & 0,010 & \multirow{7}{*}{81,8} & \multirow{7}{*}{7,874} & \multirow{7}{*}{0,446} & \multirow{7}{*}{27,330} & \multirow{7}{*}{0,000} \\
\hline & ESTR & ,077 & 0,006 & & & & & \\
\hline & EXT &,- 106 & 0,170 & & & & & \\
\hline & DUAL & $-2,651$ & 0,085 & & & & & \\
\hline & TAM & 1,934 & 0,004 & & & & & \\
\hline & LIQ &,- 120 & 0,260 & & & & & \\
\hline & Constante & $-5,817$ & 0,448 & & & & & \\
\hline \multirow{6}{*}{7} & CONC &, 046 & 0,015 & \multirow{6}{*}{80,7} & \multirow{6}{*}{14,748} & & & \\
\hline & ESTR &, 066 & 0,008 & & & & & \\
\hline & EXT &,- 110 & 0,149 & & & & 25087 & 0000 \\
\hline & DUAL & $-2,655$ & 0,078 & & & 0,064 & $25,98 /$ & 0,000 \\
\hline & TAM & 2,004 & 0,002 & & & & & \\
\hline & Constante & $-5,732$ & 0,448 & & & & & \\
\hline & CONC &, 044 & 0,015 & & & & & \\
\hline & ESTR & ,064 & 0,010 & & & & & \\
\hline 8 & DUAL &,- 697 & 0,228 & 784 & 17650 & 0024 & 23816 & 0000 \\
\hline 8 & TAM & 1,764 & 0,004 & 18,4 & $1 /, 659$ & 0,024 & 23,816 & 0,000 \\
\hline & Constante & 15,038 & 0,001 & & & & & \\
\hline & CONC &, 046 & 0,012 & & & & & \\
\hline & ESTR & ,067 & 0,009 & & & & & \\
\hline 9 & TAM & 1,721 & 0,004 & 75,0 & 12,131 & 0,145 & 22,316 & 0,000 \\
\hline & Constante & $15,113^{-}$ & 0,001 & & & & & \\
\hline
\end{tabular}

Fonte: Dados da pesquisa

Corrar, Paulo e Dias Filho (2009) abordam que o teste HLT consiste em um teste Quiquadrado que objetiva testar a hipótese de que não há diferença entre os resultados preditos pelo modelo e os observados, sendo que, quanto maior o nível de significância neste teste, melhor. Para os mesmos autores o teste dos coeficientes do modelo (OTMC) testa a hipótese de que todos os coeficientes da equação logística são nulos, caso os resultados sejam Características Determinantes das Companhias do Novo Mercado que Adotam o Hedge Accounting 
significativos, pode-se rejeitar a hipótese que todos os parâmetros estimados são nulos, ou seja, eles contribuem para melhorar a qualidade das predições. A realização dos vários testes na regressão logística é importante para validar adequadamente o modelo proposto.

Na Tabela 3 observou-se que os resultados das etapas 1, 2, 3 e 4 não apresentaram significativas diferenças entre os testes e o percentual de aproximação, sendo que o percentual de acerto dos modelos foi 78,4\% da classificação inicial, para as 4 etapas os resultados dos testes OTMC apresentara nível de significância satisfatório, porém, os resultados dos testes HLT não apresentaram significância. Dessa forma, não é possível afirmar que as características destes 4 modelos podem explicar a adoção do hedge accounting pelas companhias. Nota-se que, a retirada das características BIG4, CAUD e ROA dos modelos não interferiram nos resultados, portanto, é possível inferir que: a adoção dos serviços BIG 4, que segundo DeAngelo (1981) seriam as empresas mais qualificadas; a existência do comitê de auditoria - CAUD, que de acordo com Ho e Wong (2001), proporcionariam maior nível de evidenciações voluntárias; que a alavancagem financeira e ROA, segundo Silva (2004), seriam mais elevados em companhias que zelam pelo aprimoramento das melhores práticas de governança; não estariam interferindo na adoção voluntária da norma contábil do hedge accounting.

Na quinta etapa (Tabela 3), houve a retirada da característica INST, que representava a participação do investidor institucional, sendo que isso proporcionou uma pequena melhora no modelo que apresentou um percentual de aceitação de $80,7 \%$ da classificação inicial, e o teste de OTMC mostrou-se ser significativo, porém, este modelo ainda não pode ser aceito, pois apresenta falta de significância no teste HLT. Na sexta etapa o modelo melhorou novamente, pois foi excluída a característica END que demonstra o índice de endividamento das companhias pesquisas. Mesmo retirando esta variável, o modelo ainda não pode ser aceito por apresentar o teste HLT sem significância, apesar de apresentar um percentual de acerto do modelo de $81 \%$ e significância no teste OTMC. Na sétima etapa foi eliminada a variável LIQ, que evidencia a liquidez corrente e melhorou o modelo. Mesmo apresentando satisfatória significância no teste OTMC e representativa melhora na significância do teste HLT, o modelo não pode ser aceito devido à baixa significância deste último teste. Na oitava etapa o modelo apresentou pequena melhora com a retirada da variável EXT que contribuiu para aumentar a significância do teste HLT, apesar de reduzir ainda mais o percentual de acerto do modelo para 78,4\%. A significância do teste OTMC se manteve igual aos modelos anteriores.

Por fim, a nona etapa apresentou o modelo sem a variável DUAL que representa a participação de um ou mais executivos no Conselho de Administração como membros. Analisaram-se as limitações do modelo para fins preditivos, conforme a indicação do poder de explicativo do modelo de regressão dado pelo valor do indicador de Nagelkerke $R$ Square de 0,319 , com o percentual de acerto do modelo de $75 \%$. A retirada dessa variável proporcionou o melhor modelo, sendo que o mesmo pode ser aceito, com satisfatória significância nos testes HLT E OTMC, e também significância satisfatória nas variáveis do próprio modelo, tais como: concentração acionária (CONC), investidor estrangeiro (ESTR) e tamanho da empresa em ativos totais (TAM). Com isso, obtêm-se a confirmação da inferência que as companhias que adotam o hedge accounting apresentam elevados percentuais de ativos totais, participação de investidor estrangeiro e concentração acionária. Este resultado converge com o resultado da Tabela 2, que realizou a correlação de Pearson entre as variáveis, e está em consonância com os seguintes autores: Labelle (2002); Haniffa, R.M.; Cooke, T. E (2002); IBGC (2010), Jiang, Habib e Hu (2010); Wallace, Naser (1995); Wallace, Naser, Mora (1994). Todos os autores mencionados, de modo geral, abordam que a concentração acionária, tamanho da empresa e investidor estrangeiro são fatores que contribuem para melhorar evidenciação contábil e a adoção de melhores práticas administrativas e contábeis. 
Pela Tabela 3, observou-se também que nas etapas 5, 6, 7, 8 e 9 foram descartadas do outras características que explicavam o modelo, entretanto não eram significativas, tais como: a variável INST, que representa o percentual de participação do investidor institucional, e que segundo Tan e Keeper (2008) a participação do mesmo poderia proporcionar práticas administrativas menos difusas; a variável END, que representa o percentual de endividamento, e que conforme Procianoy e Schnorrenberger (2004), o mesmo estaria negativamente relacionado com a evidenciação contábil; a variável LIQ que representa o índice de liquidez corrente, que segundo Wallace, Naser (1995), as empresas com baixa liquidez estariam mais preocupadas com o disclosure; a variável EXT indica o percentual de membros externos do conselho de administração, que de acordo com Ho e Wong (2001), a existência de um conselho totalmente independente proporcionaria a adoção das melhores práticas de evidenciação contábil; e também que a variável DUAL que representa a participação de um diretor executivo como membro do conselho, que segundo IBGC (2010) poderia estar gerando maior conflito de interesses entre Diretores Executivos e Acionistas. Todas estas variáveis estavam inclusas na etapa 4 e cada uma delas foi sendo retirada, melhorando gradativamente o modelo.

\section{Considerações finais}

O estudo teve como objetivo principal analisar se características financeiras e de governança corporativa discriminariam as empresas que adotam as práticas contábeis de hedge accounting para a gestão de risco. Foram investigadas as companhias pertencentes ao novo mercado por meio da amostra constituída por 88 entidades, obtiveram-se dois grupos, um com 62 empresas que não apresentavam operações de hedge ou apresentavam as mesmas operações e não adotavam a norma contábil, e outro grupo com 26 empresas que realizavam operações de hedge e adotavam o hedge accounting.

Com análise de correlação de Pearson infere-se que as empresas que adotaram a contabilidade de hedge não apresentaram resultados superiores (ROA). Outras características que apresentaram fraca relação foram observadas, com isso infere-se que a participação dos investidores institucionais, endividamento elevado, a baixa liquidez corrente e maior percentual de membros externos no conselho de administração contribui pouco para a adoção do hedge accounting.

O resultado do modelo de regressão logística apontou as características mais significativas que explicam a adoção do hedge accounting: maior concentração acionária, participação do investidor estrangeiro e tamanho da empresa. Dessa forma, é possível inferir no grupo pesquisado, que a estrutura de capital encontra-se concentrada a poucos acionistas, que estão preocupados com a adoção do hedge accounting e buscam mitigar os riscos financeiros da companhia. O significativo número de empresas com capital estrangeiro ter operação de hedge, poderia estar sendo explicada pelo profissionalismo dos investidores estrangeiro na adoção de práticas muito comuns no mercado de capitais mundial. A relação do hedge accounting com o tamanho poderia estar sendo assentada na inferência de que grandes companhias normalmente estariam mais interessadas na evidenciação contábil para buscar reduzir o seu custo de capital.

Como sugestão para futuros estudos, salienta-se que outras características poderiam ser analisadas para avaliar o resultado da adoção do hedge accounting junto ao mercado de capitais, ou seja, verificar se a adoção da norma proporcionou realmente maior transparência por meio da evidenciação contábil, verificando o nível de risco das ações das companhias que adotaram a contabilidade de hedge. 


\section{Referências}

AEBI, V.; SABATO, G.; SCHMID, M.; Risk management, corporate governance, and bank performance in the financial crisis. Journal of Banking \& Finance, 2011.

AHMED, K; NICHOLLS, D. The impact of non-financial company characteristics on mandatory disclosure compliance in developing countries: The case of Bangladesh. The International Journal of Accounting. Urbana: 1994. v. 29, n. 1; p. 62.

ARAUJO, C. G.; IKUNO, L. M.; PAULO, E.; SALES, I. C. H. Hedge accounting: análise da extensão de sua utilização nas empresas brasileiras que compõem o IBRX-100. $11^{\circ}$

Congresso USP de Controladoria e Contabilidade. Anais... São Paulo/SP, 2011.

BERNSTEIN, P. Desafio aos deuses: a fascinante história do risco. 3. Ed., Campus, Rio de Janeiro, 1996.

BHIMARI, A. Risk management, corporate governance and management accounting: Emerging interdependencies. Manangement accounting Research, 2009.

BM\&FBOVESPA. Disponível em: http://www.bmfbovespa.com.br/home.aspx?idioma= ptbr. Acesso em: 12.mar. 2013.

BOGONI, N. M.; FERNANDES, F. C. Gestão de risco nas atividades de investimento nos regimes próprios de previdência social (RPPS) dos municípios do Estado do Rio Grande do Sul. Revista Eletrônica de Administração. Escola de administração da UFRGS. 2011.

\section{COMMITTEE OF SPONSORING ORGANIZATIONS OF THE TREADWAY}

COMMISSION - COSO. Enterprise Risk Management - Integrated Framework. New Jersey: AICPA, 2004

CORRAR, L. J.; PAULO, E.; DIAS FILHO, J. M.; Análise Multivariada: para os cursos de administração, ciências contábeis e economia. 1. ed. 2. reimpr. São Paulo: Atlas, 2009.

DeANGELO, L. E. Auditor independence, low balling, and disclosure regulation. Journal of Accounting and Economics, n. 3, 1981, p. 113-127

DUTRA, M. G. L.; SAITO, R. Conselhos de administração: análise de sua composição em um conjunto de companhias abertas brasileiras. Revista de Administração Contemporânea. São Paulo, v. 6, n. 2, p. 9-27, 2002.

FÁVERO, L. P., BELFIORE, P., SILVA, F., L., CHAN, B. L. Análise de dados: Modelagem multivariada para tomada de decisões. São Paulo: Elsevier, 2009.

FERNANDES, F.C., MOURA, G.D., ORO, I. M., SANTANA, S.V., Evidenciação obrigatória de hedge accounting em companhias abertas listadas no índice de sustentabilidade empresarial (ISE). XIV ENGEMA - Encontro nacional sobre gestão empresarial e meio ambiente, São Paulo, 2012.

GUAY, W. R. The impact of derivatives on firm risk: An empirical examination of new derivative users. Journal of Accounting and Economics, v. 26, p. 319-351, 1999. 
KOTHARI, S. P. How much do firms hedge with derivatives? Journal of Financial Economics, v. 70, 2003.

GLAUM, M; KLÖCKER, A. When the tail wags the Dog: hedge accounting and its influence on financial hedging. Accounting and Business Research, Forthcoming, 2011. Disponível em: 〈http://ssrn.com/abstract=1804813 >. Acesso em: 12 Mar. 2013.

HANIFFA, R.M.; COOKE, T. E Cooke. Culture, corporate governance and disclosure in Malaysian corporations. Abacus, 38 (3), 2002, p. 317-349

HEALY, P. M.; PALEPU, K. G. Information asymmetry, corporate disclosure, and the capital markets: a review of the empirical disclosure literature. Journal of Accounting and Economics, vol. 31, p. 405-440. 2001. <http://dx.doi.org/10.1016/ S0165-4101(01)00018-0>. Acesso em: 18 fev. 2013.

HO, S.S. M.. WONG, K. S. A study of the relationship between corporate governance structures and the extent of voluntary disclosure, Journal of international accounting, auditing and taxation, 2001.

IATRIDIS, G., Accounting disclosure and firms' financial attributes: Evidence from the UK stock market. International. Review of Financial Analysis, p. 219-24. 2008. Disponível em: <www.sciencedirect.com> Acesso em: 22 mar 2013.

INSTITUTO BRASILEIRO DE GOVERNANÇA CORPORATIVA - IBGC. Código das Melhores Práticas de Governança Corporativa. Disponível em: <http://www.ibgc.org.br.> Acesso em 03 fevereiro de 2013.

JIANG, H; HABIB, A.; HU, B. ; Ownership concentration, voluntary disclosures and information asymmetry in New Zealand. The British Accounting Review, 2010.

KIRKPATRICK, G., The Corporate Governance Lessons from the Financial Crisis, Financial Market Trends, OECD, 2009.

LA PORTA, R. et al. Investor protection and corporate governance. Journal of Financial Economics, v. 58, p. 3-27, 2000.

LABELLE, R. The statement of corporate governance practices (SCGP). A Voluntary Disclosure and CorporateGovernance Perspective. Jun, 2002. Disponível em: <http://dx.doi.org/10.2139/ssrn.317519>. Acesso em: 05 mai. 2013

LANG, W.W., JAGTIANI, J. A. The Mortgage and Financial Crises: The Roles of Credit Risk Management and Corporate Governance. International Atlantic Economic Society, jul. 2010, n.38, p.295-316, 2010.

LAUDELINO, J. A. DE S. Evidenciação de riscos de empresas que captam recursos no mercado de capitais brasileiro: um estudo do setor de energia elétrica. $183 \mathrm{f}$. Dissertação (Mestrado em Ciências Contábeis) - Universidade Regional de Blumenau, Blumenau, 2008. 
MOURA, G. D.; MACÊDO; F. F. R. R; HEIN, N. Investidores institucionais e boas práticas de governança corporativa: uma análise das maiores empresas brasileiras listadas na BOVESPA. Congresso Anpcont. 5, Vitória-ES, jun, 2011.

ORGANISATION FOR ECONOMIC CO-OPERATION DEVELOPMENT OECD.OECD principles of corporate governance. Disponível em: <http://www.oecd.org>. Acesso em: 14/03/2013.

SILVEIRA, A. D. M. Governança corporativa, desempenho e valor da empresa no Brasil. Dissertação (Mestrado em Administração) - Programa de Pós-Graduação em Administração da Universidade de São Paulo, São Paulo, 2002.

O caso Sadia - Sete erros que levaram a companhia a sucumbir no escândalo dos derivativos cambiais. Fev. 2013. Disponível em: <www.ibgc.org.br> Acesso em: 15 fev, 2013.

SLOAN, R. G. Financial accounting and corporate governance: an discussion. Journal of Accounting and Economics. v. 32, p. 335-347, 2001.

TAN, A. W.; KEEPER, T. B Institutional Investors and Corporate Governance: A New Zealand Perspective. Working Papers, v. 65, Centre for accounting, Governance and Taxation Research, School of Accounting and Commercial Law, 2008.

VAISSIÉ, M., Solvency II: A unique opportunity for hedge fund strategies. Research Associate, EDHEC-Risk Institute, Senior Portfolio Manager, Lyxor AM, 2012. Disponível em:www.edhec-risk.com Acessado em 22 de mar de 2013.

ZONATTO, V.C.S., BEUREN, I. M., Categoria de riscos evidenciados nos relatórios de administração de empresas brasileiras com ADRs. Revista Brasileira de Gestão de Negócios, São Paulo, v.12, n.35, p.141-155, abr-jun, 2010.

WALLACE, R S O.; NASER, K. Firm-specific determinants of the comprehensiveness of mandatory disclosure in the corporate annual reports of firms listed on the stock exchange of Hong Kong. Journal of Accounting and Public Policy. New York: Winter, 1995.

MORA, A. The relationship between the comprehensiveness of corporate annual reports and firm characteristics in Spain. Accounting and Business Research. Kingston Upon Thames: Winter 1994. 